\title{
INTRASPECIFIC NEIGHBOUR EFFECTS ON THE GROWTH AND MORPHOLOGICAL PLASTICITY OF SALVINIA MOLESTA
}

\author{
S.M. SOLANGAARACHCHI and H.T. HAPUARACHCHI \\ Department of Botany, University of Kelaniya, Kelaniya..
}

(Received: 17 October 1994; accepted : 23 February 1995)

\begin{abstract}
The tropical fresh water fern salvinia (Salvinia molesta D.S. Mitchell) is a problematic weed and is being controlled biologically by the introduction of a weevil, Cyrtobagous salviniae. The plant consists of three morphologically different growth forms; primary, secondary and tertiary, during its growth. The present paper describes how the initial density of primary stage plants affected its morphological plasticity. Primary stage apical cuttings consisting of three ramets (uniform in size) were selected and were grown at densities of 16, 400 and 800 ramets per square metre. The growth and morphological changes were observed for a period of $100 \mathrm{~d}$. Plants remained at their primary stage under the lowest density and they transformed from primary to secondary and then to tertiary growth stages at higher densities. There were significant differences between the growth forms and their growth.
\end{abstract}

Key words: Intraspecific neighbour effect, Salvinia.

\section{INTRODUCTION}

A plant may show a change in its development pattern, during its life cycle,which may start with the germination of a seed, continuation with a juvenile phase which grows exponentially and transformation into maturity phase during which the plant is capable of changing from vegetative to reproductive phase producing flowers, fruits and the production of a new generation of seeds. This may be followed by a state of senescence.

As early as in 1889 Goebel $^{1}$ concluded that some plants show heteromorphism between the juvenile and mature phases. During this transition plants show distinctive morphology of leaves, stems and other structures, and also change in growth rate. In different plant species the duration of each growth form differs. In Xanthium sp. juvenile leaf forms may occur only on the first or first several nodes of the germinating seedling. Juvenile types of stem growth, leaf form and thorniness persist for four to ten years in Citrus spp.

A plant may regulate these changes as adaptations to different environmental conditions. The timing of the onset and emergence from dormancy of plants in temperate and arctic climates can also be considered as such adaptations.

The fern salvinia (Salvinia molesta D.S. Mitchell) which is an aquatic weed in tropical fresh waters also shows some morphological plasticity during its growth. The plant is sterile ${ }^{2}$ and the entire species can be considered as a single genet without any genetic variations. Therefore the population dynamics depend on branching, growth and fragmentation. The plant consists of pairs of floating leaves, submerged root-like structures at each node along the stolon. 
Room $^{3}$ has reported that there are three lateral buds in each alternate leaf axil, and the sequence of their development is from apical to first, to second and then to third rank. Under natural conditions, it is always the first rank bud that develops into a branch whereas the second and third rank buds develop in high nutrient conditions such as in sewage treatment lagoons. Reproductive structures consisting of an axis bearing sporocarps are produced among the rootlike structures. The upper surface of the floating leaf is covered with multicellular papillae, on the apex of which there is an arrangement of four hairs that are united at their tips to form a bird - cage like structure. The rest of the surface of the plant is covered by uniseriate, multi-cellular, pointed hairs.

It has been observed by Mitchell ${ }^{4}$ that there are three morphologically distinctive growth forms and they are produced in response to environmental conditions. When the plant is growing in deep shade or in rich nutrient conditions or is in the first stage of invasion of an area, it produces small leaves upto $1.5 \mathrm{~cm}$ in width. These leaves float flat on the water surface. Internodes are long and leaves do not overlap one another. Growth rate is very high and it is termed as the "primary-invading form". The leaves of the secondary growth form or "open-water-colonizing form" which is transitional between the first and third forms, are more than $2.0 \mathrm{~cm}$ in width, and become deeply keeled and boat-shaped and leaf undersurface still lying in contact with the water surface, and leaves do not overlap. The tertiary stage which is characteristic "mat form" bears sporocarps. Internodes are relatively shorter and the floating leaves are larger (upto $6.0 \mathrm{~cm}$ in width). The leaves are bilobed and conduplicately folded along the midrib and the leaves remain above the water surface.

The effect of immediate neighbours on plant growth has been observed by Darwin in $1859 .^{5}$ These neighbours may be intraspecific and interspecific. ${ }^{6}$ Majority of the intraspecific neighbour effects (density effects) have been exercised with plants of single upright stems and the mortality and reduced size of surviving genets have been reported..$^{7 \cdot 9}$

But in clonally spreading plants density stress may affect more at the modular level than at the genet level. Reduced tiller numbers in grass, Lolium perenne L. , ${ }^{10}$ and reduced node number and number of branches in Trifolium repens $\mathrm{L}^{11-13}$ under high densities have been reported.

The present paper describes the results of an experiment designed to study the effect of the initial density of plants of Salvinia on their growth with special reference to their morphological plasticity. Knowledge on the above aspects could be of great importance in controlling of Salvinia.

\section{METHODS AND MATERIALS}

Cement pond of $5 \times 3 \times 1 \mathrm{~m}$ in the Botanical Garden of the Department of Botany, University of Kelaniya was filled upto $25 \mathrm{~cm}$ with mud brought from a water body where Salvinia was growing. It was then filled with water upto $90 \mathrm{~cm}$ in height and this level was maintained throughout the experiment by adding pond 
water whenever necessary. Therefore it was assumed that the nutrient levels in this pond maintained more close to natural pond water. Wooden frames (quadrats) of $25 \times 25 \mathrm{~cm}$ were placed afloat.

Uniform (size) apical cuttings consisting of three nodes were selected from a healthy clone of $S$. molesta at its primary form. Each quadrat was allocated to one of the following three density treatments.

Treatment 1 ( $\mathrm{D}_{1}$ - Control) - 1 plant per quadrat (density $\left.=16 \mathrm{plants} / \mathrm{m}^{2}\right)$, Treatment $2\left(\mathrm{D}_{2}\right)-25$ plants per quadrat (density $=400$ plants $\left./ \mathrm{m}^{2}\right)$, Treatment $3\left(\mathrm{D}_{3}\right)-50$ plants per quadrat (density $=800$ plants $/ \mathrm{m}^{2}$ ).

The layout of the experiment was according to a completely randomized design. Three replicates from each treatment were harvested every five days upto 100 days. Number of leaves, number of nodes, number of branched nodes, mean internode length and the length of the main stolon, mean leaf length, mean leaf width, mean leaf area, total leaf area, and mean length of roots were measured for each plant in each frame. In treatments $D_{2}$ and $D_{3}$, ten plants were randomly selected for measurements. Plants were then washed carefully and shoots and roots were separated in each plant and were oven dried at $80^{\circ} \mathrm{C}$ until. a constant weight was recorded. The shoot/ root ratio was then calculated. The percentage of branching was also calculated.

The analysis of variance was done using MINITAB data analysis software package. Multiple comparison tests were carried out for the comparison between three treatments using Sheffe's method. ${ }^{14}$ This experiment has been carried out thrice and the results were more or less similar and the present paper describes the results of the third experiment.

\section{RESULTS}

The single plants in treatment $1\left(\mathrm{D}_{1}\right.$ - Control) remained at their primary stage throughout the experimental study. Plants in the other two treatments $\left(\mathrm{D}_{2}\right.$ and $\mathrm{D}_{3}$ ) remained at primary stage upto 25 days in all treatments and became secondary and finally after 45 days tertiary. However, there was no significant difference between $\mathrm{D}_{2}$ and $\mathrm{D}_{3}$ treatments . During primary stage, leaves were small and oval shaped and did not overlap one another. Boat shaped leaves were found during the secondary stage. During tertiary stage the leaves became large bilobed and folded along the midrib. Internode length became relatively short and the leaves overlapped one another. Sporocarps could be seen only in plants at tertiary stage.

Table 1 shows the overall means of number of leaves, nodes, branched nodes, branching percentage, mean internode length, length of the main stolon, mean leaf length, mean leaf width, mean leaf area, total leaf area, mean length of roots, dry weights of shoots, roots and whole plants, and shoot/root ratio per individual plant in each treatment. 
Table 1: Comparison of the effect of initial density of ramets on morphological changes of Salvinia molesta.

\begin{tabular}{lrrr}
\hline \multicolumn{1}{c}{ Variable } & \multicolumn{1}{c}{$\mathrm{D}_{1}$} & \multicolumn{1}{c}{$\mathrm{D}_{2}$} & \multicolumn{1}{c}{$\mathrm{D}_{3}$} \\
\hline Number of leaves & $68.87 \pm 2.14^{\mathrm{a}}$ & $30.73 \pm 1.43^{\mathrm{b}}$ & $30.80 \pm 1.43^{\mathrm{b}}$ \\
Number of nodes & $39.00 \pm 1.61^{\mathrm{a}}$ & $17.60 \pm 1.08^{\mathrm{b}}$ & $17.93 \pm 1.09 \mathrm{~b}^{\mathrm{b}}$ \\
Number of branched nodes & $4.52 \pm 0.55^{\mathrm{a}}$ & $1.61 \pm 0.33^{\mathrm{b}}$ & $1.53 \pm 0.32^{\mathrm{b}}$ \\
Percentage branching & $12.94 \pm 0.93^{\mathrm{a}}$ & $8.10 \pm 0.73^{\mathrm{b}}$ & $6.83 \pm 0.67^{\mathrm{c}}$ \\
Mean internode length (cm) & $1.19 \pm 0.28^{\mathrm{a}}$ & $0.77 \pm 0.23^{\mathrm{b}}$ & $0.77 \pm 0.23^{\mathrm{b}}$ \\
Length of the main stolon (cm) & $11.97 \pm 0.89^{\mathrm{a}}$ & $9.94 \pm 0.81^{\mathrm{b}}$ & $9.70 \pm 0.80^{\mathrm{b}}$ \\
Mean leaf length (cm) & $1.40 \pm 0.31^{\mathrm{a}}$ & $1.47 \pm 0.31^{\mathrm{a}}$ & $1.46 \pm 0.31^{\mathrm{a}}$ \\
Mean leaf width (cm) & $1.25 \pm 0.30^{\mathrm{a}}$ & $1.57 \pm 0.32^{\mathrm{a}}$ & $1.67 \pm 0.33^{\mathrm{a}}$ \\
Mean leaf area (cm $\left.{ }^{2}\right)$ & $2.11 \pm 0.20^{\mathrm{a}}$ & $3.15 \pm 0.53^{\mathrm{b}}$ & $3.50 \pm 0.58^{\mathrm{b}}$ \\
Total leaf area (cm $\left.{ }^{2}\right)$ & $185.40 \pm 3.51^{\mathrm{a}}$ & $136.22 \pm 3.01^{\mathrm{a}}$ & $152.68 \pm 3.1^{\mathrm{a}}$ \\
Mean length of roots (cm) & $4.10 \pm 0.52^{\mathrm{a}}$ & $4.62 \pm 0.55^{\mathrm{a}}$ & $5.24 \pm 0.60^{\mathrm{a}}$ \\
Dry weight of shoots (g) & $0.19 \pm 0.11^{\mathrm{a}}$ & $0.11 \pm 0.08^{\mathrm{a}}$ & $0.14 \pm 0.10^{\mathrm{a}}$ \\
Dry weight of roots (g) & $0.13 \pm 0.10^{\mathrm{a}}$ & $0.06 \pm 0.06^{\mathrm{a}}$ & $0.07 \pm 0.06^{\mathrm{a}}$ \\
Dry weight of whole plants (g) & $0.31 \pm 0.14^{\mathrm{a}}$ & $0.16 \pm 0.10^{\mathrm{a}}$ & $0.21 \pm 0.12^{\mathrm{a}}$ \\
Shoot/root ratio & $1.48 \pm 0.37^{\mathrm{a}}$ & $1.91 \pm 0.35^{\mathrm{a}}$ & $1.84 \pm 0.33^{\mathrm{a}}$ \\
\hline
\end{tabular}

Each value is an overall mean of all replicates at all harvests of each treatment. $\left(D_{1}=16\right.$ plants $/ \mathrm{m}^{2}$ Control, $\mathrm{D}_{2}=400$ plants $/ \mathrm{m}^{2}, \mathrm{D}_{3}=800$ plants $\left./ \mathrm{m}^{2}\right)$. Means $\pm \mathrm{SE}$ sharing the same letter within each row do not differ significantly $(\mathrm{p}<0.05)$.

Control plants bore significantly highest number of leaves $(p<0.05)$. In the other two treatments $\left(\mathrm{D}_{2}\right.$ and $\left.\mathrm{D}_{3}\right)$, it has reduced by $55 \%$ (Table 1 ). However, number of leaves were more or less similar in all three treatments upto 40 days (Fig. 1a). During this period the leaf number has increased at the rate of 0.625 per day in the control plants. Thereafter, it has increased at the rate of 2.5 leaves per day. Plants at higher densities have increased their leaves at the rate of 0.6 per day upto 25 days (i.e. during their primary stage). Thereafter leaf number increased at the rate of 0.8 per day.

The number of nodes and branched nodes also showed a similar trend as with the number of leaves. The greatest number of branched nodes were found in control plants and it has significantly $(p<0.05)$ decreased by $64 \%$ in the two density treatments (Table 1 \& Fig. 1b). Branching percentage was also greatest in the control plants and it has reduced by $37 \%$ and $47 \%$ in the low density and high density treatments respectively.

Mean internode length was greatest in control plants whilst it has significantly $(\mathrm{p}<0.05)$ reduced by $35 \%$ in the two density treatments. Length of the main stolon also has reduced at higher densities. The reduction was $18 \%$ of the control. 

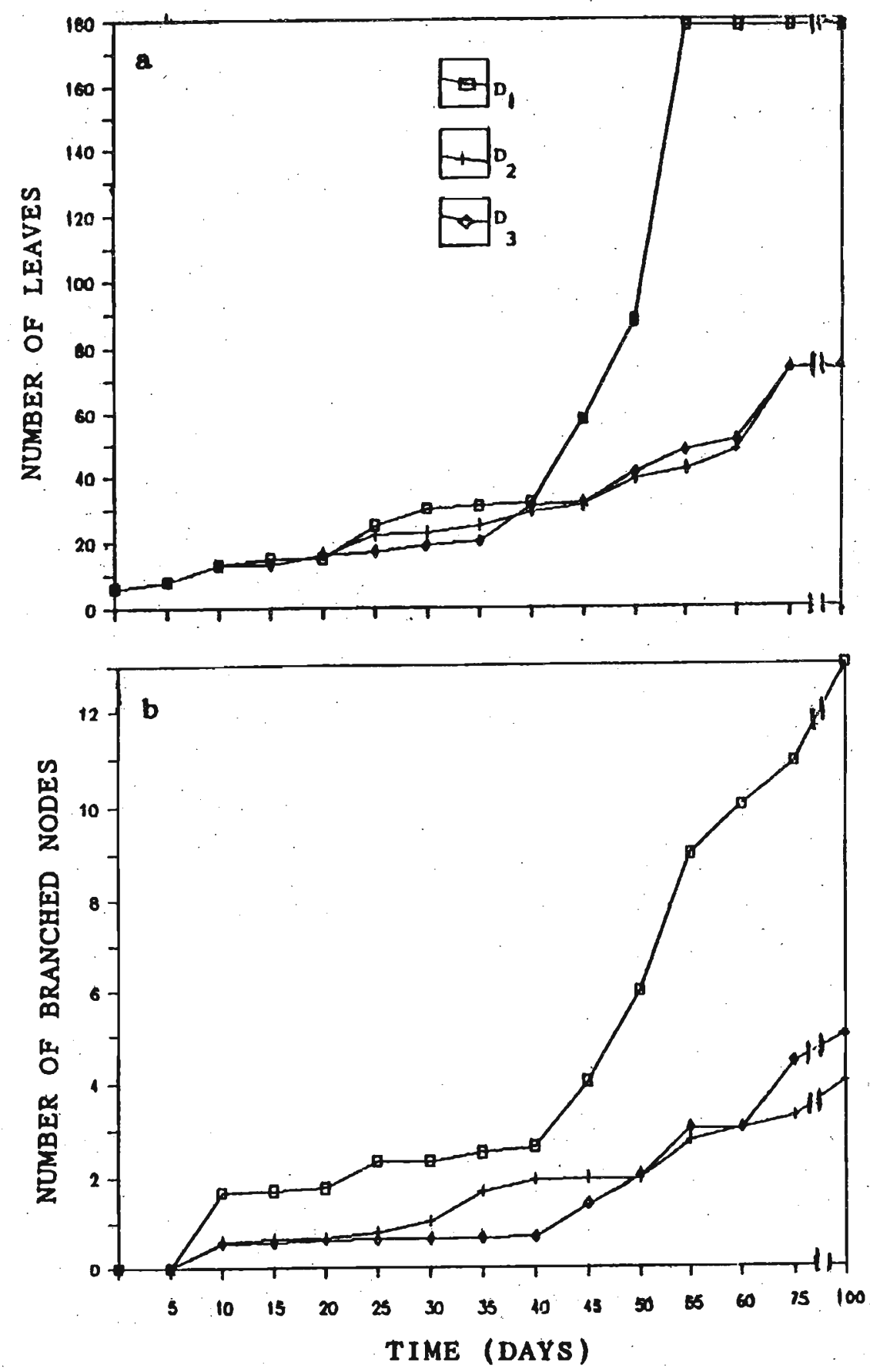

Figure 1: Comparison of number of leaves and number of branched nodes in each Salvinia plant grown under three different densities $\left(D_{1}=16\right.$, $D_{2}=400$ and $D_{3}=800$ plants per square metre). a. Number of leaves, b. Number of branched nodes. 
Mean leaf length and mean leaf width did not show any significant difference between treatments (Table 1). But the mean leaf area was significantly $(p<0.05)$ smaller in control plants (i.e. plants of primary stage). However, the total leaf area per plant did not show any significant difference between treatments (Table 1). Mean length of roots, dry weights of shoots, roots and whole plants and shoot/root ratio also did not show any significant difference between treatments.

\section{DISCUSSION}

The results showed significant morphological and growth difference between the control and higher density treatments during the growth period. At lower densities plants remained at primary stage and at higher densities they transformed into secondary and then to tertiary stages. Eventhough there were no significant differences between the effects of the two selected densities $\left(D_{2}\right.$ \& $\mathrm{D}_{3}$ ), if intermediate density treatments were also included in the present study, significant differences would have been observed between treatments.

The effect of density was to reduce the growth and branching of single plants and hence they are smaller in size. Branching adds new nodes which bear buds. Reduced growth could be attributed to reduced branching. Similar results have also been shown with other clonally spreading species. ${ }^{10-13}$ Reduced branching was due to the inhibition of the development of axillary meristems. At primary stage Leaf Area Index (LAI) as estimated was 3.0 and they were 5.45 and 12.21 in $\mathrm{D}_{2}$ and $\mathrm{D}_{3}$ treatments respectively.

Thus, at higher densities bud sites may be naturally shaded by leaves of individuals, ${ }^{15}$ whereas at lower densities, as the individual plants are spaced apart, the natural shading may have occurred to a lesser extent. ${ }^{16,17}$ When there is natural shading, not only the quantity but also the quality of light may change. e.g. Red/Far red ratio is reduced as the red light is selectively absorbed by chlorophyll pigments present in leaf canopies. Reduced Red/Far red ratio also has shown to be inhibitory on the further development of axillary buds and hence reduced branching. ${ }^{17}$

Within water bodies, Salvinia plants are dispersed mainly by wind and water currents. It may provide a chance for plants to grow at low densities which again may increase their growth rate and branching percentage. Therefore, it would be economical if the Salvinia population can be prevented from dispersing during control efforts.

The influences exerted by Salvinia to the water bodies vary according to their growth stages. Plants remained at the primary stage at lower densities and at higher densities they became tertiary. Thus the primary stage, plants have fewer nodes, smaller leaves (hence smaller $\mathrm{LAI}$ ) and roots per unit area of the water surface allowing more light penetration into the water. Smaller number of nodes implies smaller number of bud sites and hence less regeneration potential. On the other hand, the tertiary plants, form a very thick layer (about 
$1 \mathrm{~m}$ in depth) consisting of greater number of nodes, leaves and roots. Larger leaves and a higher number of roots reduce the amount of light penetration into the water, and this affects both flora and fauna in the medium. The potential regeneration is greater as they have a greater number of bud sites. The chance of regeneration of these buds may also be greater due to its greater initial capital than that in the primary stage. Thus the primary stage plants influence the water body at a minimum level in comparison to tertiary stage (The effects of secondary stage may lie intermediate between the primary and tertiary stages, but as it is a transitional stage only the two extreme stages are considered in the present discussion).

Therefore, it could be suggested that if this weed could be controlled during its primary stage, mechanically, at least in manageable water bodies, the result would be quicker, less problematic and less expensive than its control during its tertiary stage. If this form is allowed to grow longer, then they become tertiary which affects the waterbody more harmfully.

\section{Acknowledgement}

Authors thank colleagues in the Department of Botany, University of Kelaniya for assistance.

\section{References}

1. Goebel K. (1889). Uber die jugen dzustande der Pflanzen. Flora 72: 1-45.

2. Grewal R.K. (1966). Cytological study on sterility in Salvinia auriculata Aubl. with a bearing on its reproductive mechanism. Cytologia 31: 330-338.

3. Room P.M. (1985). Plant architecture and how biological control agents affect the dynamics of weeds. Proceedings of the th International symposium of biological control of weeds held 19-25 August 1984. Vancouver, Canada. In Agriculture Canada (Ed E.S. Delfosse). pp.89-102.

4. Mitchell D.S. (1970). Autecological studies of Salvinia auriculata Aubl. Ph.D. thesis, University of London.

5. Darwin C. (1859). The origin of species by means of natural selection. 6 th ed., John Murray, London.

6. Clegg L. (1978). The morphology of clonal growth and its relevance to the population dynamics of perennial plants. Ph.D. thesis, University of Wales.

7. Donald C.M. (1951). Competition among pasture plants. I. Intra-specific competition among annual pasture plants. Australian Journal of Agricultural Research 2: 355-376. 
8. Kira T.H. , Ogawa \& Shinozaki K. (1953). Intraspecific competition among higher plants. I. Competition density yield inter-relationships in regularly dispersed populations. Journal of the Institute of Polytechnic Osaka City. University 4: 1-16.

9. Kobayashi S. (1975). Growth analysis of plants as an assemblage of internodal segments a case of sunflower plants in pure stand. Japanese Journal of Ecology 25: 61-70.

10. Kays S. \& Harper J.L. (1974). The regulation of plant and tiller density in a grass-sward. Journal of Ecology 62: 97-105.

11. Erith A.G. (1924). White clover(Trifolium repens L.). A monograph. Duckworth, London.

12. Harvey H.J. (1978). The regulation of vegetative reproduction. Ph.D. thesis, University of Wales.

13. Solangaarachchi S.M. (1985). The nature and control of branching pattern in white clover (Trifolium repens L.). Ph.D. thesis, University of Wales.

14. Sokal R.R. \& Rohlf F.J. (1973). Introduction to biostatistics. pp. 254-257. W.H. Freedman and Company, San Francisco.

15. Black J.N. (1960). The significance of petiole length, leaf area and light interception in competition between strains of subterranean clover (Trifolium subterraneum L.) growth in swards. Australian Journal of Agricultural Research 11: 277-291.

16. Trautner J.L. \& Gibson P.B. (1966). Fate of white clover axillary buds at five intensities of sunlight. Agronomy Journal 58: 557-559.

17. Solangaarachchi S.M. \& Harper J.L. (1987). The effect of canopy filtered light on the growth of white clover (Trifolium repens). Oecologia (Berlin) 72: $372-378$. 